\title{
Zingiber officinale Extract (ZOE) Incorporated with Layered Double Hydroxide Hybrid through Reconstruction to Preserve Antioxidant Activity of ZOE against Ultrasound and Microwave Irradiation
}

\author{
Hyoung-Jun Kim ${ }^{1,+}$, Su-Bin Lee ${ }^{1,+}$, Ae-Jin Choi ${ }^{2}$ and Jae-Min Oh ${ }^{1, *}$ \\ 1 Department of Energy and Materials Engineering, Dongguk University-Seoul, Seoul 04620, Korea \\ 2 Department of Agrofood Resources, National Institute of Agricultural Sciences of RDA, Wanju 55365, Korea \\ * Correspondence: jaemin.oh@dongguk.edu; Tel.: +82-2-2260-4977 \\ + These authors contributed equally to this work.
}

Received: 31 July 2019; Accepted: 4 September 2019; Published: 8 September 2019

check for updates

\begin{abstract}
We prepared Zingiber officinale extract (ZOE) incorporated in a layered double hydroxide (LDH) hybrid through a reconstruction method in order to preserve the antioxidant activity of ZOE from ultrasound and microwave irradiation. X-ray patterns, infrared spectroscopy, and scanning electron microscopy suggested that ZOE moieties were encapsulated in the interparticle space of reconstructed LDH, thus preserving its intact structure. Dynamic light scattering and zeta-potential measurement also supported the hypothesis that ZOE moieties were located in the interparticle pore of $\mathrm{LDH}$ rather than at the surface of LDH particles. Thermogravimetry analysis revealed that thermal stability of encapsulated ZOE could be enhanced by LDH encapsulation. Radical scavenging assay showed that antioxidant activity of ZOE-LDH hybrid was increased after ultrasound and microwave irradiation, while ZOE itself dramatically lost its antioxidant activity upon ultrasound and microwave treatment.
\end{abstract}

Keywords: layered double hydroxide; Zingiber officinale extract; antioxidant activity; ultrasound; microwave irradiation; protection

\section{Introduction}

Many natural plant extracts have antioxidant activities due to their bioactive components, such as flavonoids, phenolics, and others [1-4]. Zingiber officinale (ZO), generally known as ginger, belongs to the family Zingiberaceae, and it has been recently studied due to its nutraceutical effects like preventing oxidative stress in an animal model [5]. Gargova et al. have reported that supercritical $\mathrm{CO}_{2}$ extraction of ginger extract possesses good radical scavenging activity due to its high polyphenol content [6]. On the other hand, essential oil of ginger is known to have high antioxidant properties. It is often used as a functional food additive [7]. The antioxidant activity of $\mathrm{ZO}$ is mainly attributed to its phytochemicals, such as 6-gingerol, 8-gingerol, and 6-shogaol [8]. However, these phytochemicals can be destroyed by external damage such as ultrasound and microwave irradiation [9]. Irradiation with ultrasound can cause cleavage of the $\mathrm{H}-\mathrm{O}$ bond of $\mathrm{H}_{2} \mathrm{O}$ in an aqueous solution, resulting in hydroxyl radical and hydrogen atoms [10].

These radicals can react with organic compounds, leading to degradation of phytochemicals [11]. Sun et al. have reported that degradation of pelargonidin 3-glucoside extracted from strawberry upon ultrasound irradiation can reduce its antioxidant capacity depending on the ultrasound power [12]. Microwave irradiation can induce rapid and intensive heating of polar substances, thus accelerating the reactivity of molecules. These phenomena can decompose phytochemicals in natural plant 
extracts. Concentrations of bioactive compounds, such as chlorophyll, vitamin C, polyphenol, and flavonoid in Brussels sprouts, and radical scavenging activity have been reported to be significantly reduced with increasing microwave treatment time [13]. The antioxidant activity of ginger extract can also be significantly reduced upon microwave irradiation [14]. Therefore, external physiochemical stimuli such as ultrasound and microwave irradiation can negatively influence the antioxidant activity of phytochemicals.

To overcome this problem, many researchers have used reservoir materials, such as lipid, polysaccharide, protein, and inorganic nanoparticles to preserve biologically active but physiochemically fragile moieties [15-17]. Among these reservoirs, layered double hydroxide (LDH) is one of the emerging materials in terms of encapsulation, protection, and controlled release of biologically active species, such as drugs, therapeutic genes, vitamins, and others [18-20]. LDH structures have a positively charged metal hydroxide layer and charge-compensating interlayer anions. They usually have a relatively large specific surface area and high anion exchange capacity [21]. LDHs can encapsulate a large amount of anion species protected by LDH layers in terms of thermal, mechanical, chemical, and biological stimulations [22,23]. In our previous study, we have reported that DNA intercalation using LDH by ion-exchange can protect DNA from an external attack of DNA-destroying enzymes [24]. Preservation of vitamin C, which is vulnerable to oxidation under ambient conditions, into the interlayer of LDH can enhance its chemical stability [25]. Furthermore, it has been reported that LDH could effectively encapsulate natural extract that contains a variety of sized molecules by reconstruction method. Sand-rose or house-of-cards structure obtained by reconstruction of LDH can provide the interparticle pores to load extract moiety with various molecular weights [26].

The objective of this study was to hybridize Zingiber officinale extract (ZOE) and LDH using a reconstruction method and to investigate its antioxidant activity protection effect. Structures of pristine $\mathrm{MgFe}-\mathrm{CO}_{3}-\mathrm{LDH}$, calcined $\mathrm{LDH}$, and ZOE-incorporated $\mathrm{LDH}(\mathrm{ZOE}-\mathrm{LDH})$ hybrid were analyzed using powder X-ray diffractometer and Fourier transform infrared spectroscopy. Morphologies, particle sizes, and surface charges of pristine $\mathrm{MgFe}-\mathrm{CO}_{3}-\mathrm{LDH}$ and $\mathrm{ZOE}-\mathrm{LDH}$ hybrid were measured by scanning electron microscopy, dynamic light scattering, and zeta-potential, respectively. To determine the chemical formula of a ZOE-LDH hybrid and the thermal stability of ZOE, a thermogravimetry analysis was carried out. Finally, preservation of the antioxidant activity of ZOE by LDH encapsulation was valuated utilizing radical scavenging assay after appropriate treatment with ultrasound or microwave irradiation.

\section{Materials and Methods}

\subsection{Materials}

Magnesium nitrate hexahydrate $\left(\mathrm{Mg}\left(\mathrm{NO}_{3}\right)_{2} \cdot 6 \mathrm{H}_{2} \mathrm{O}\right)$ was obtained from Junsei Chemical CO., LTD (Tokyo, Japan). Iron nitrate nonahydrate $\left(\mathrm{Fe}\left(\mathrm{NO}_{3}\right)_{3} \cdot 9 \mathrm{H}_{2} \mathrm{O}\right)$ and 2,2-diphenyl-1-picrylhydrazyl (DPPH) were purchased from Sigma-Aldrich, Co. Inc. (St. Louis, MO, USA). Sodium nitrate (NaOH), sodium bicarbonate $\left(\mathrm{NaHCO}_{3}\right)$, and methyl alcohol, $99.5 \%$ were acquired from DAEJUNG CHEMICALS \& MATERIALS CO., LTD (Siheung, Korea). Dimethyl sulfoxide (DMSO) was obtained from TOKYO CHEMICAL INDUSTRY CO., LTD (Tokyo, Japan). Zingiber officinale extract (ZOE) using enzyme extraction method was provided by the Rural Development Administration, Republic of Korea.

\subsection{Preparation of Pristine $\mathrm{MgFe}-\mathrm{CO}_{3}-\mathrm{LDH}$}

Pristine $\mathrm{MgFe}-\mathrm{CO}_{3}-\mathrm{LDH}$ was synthesized by conventional co-precipitation method. A solution containing $\mathrm{Mg}\left(\mathrm{NO}_{3}\right)_{2} \cdot 6 \mathrm{H}_{2} \mathrm{O}(0.05 \mathrm{M})$ and $\mathrm{Fe}\left(\mathrm{NO}_{3}\right)_{3} \cdot 9 \mathrm{H}_{2} \mathrm{O}(0.025 \mathrm{M})$ was titrated with $\mathrm{NaOH} / \mathrm{NaHCO}$ $(0.25 \mathrm{M} / 0.075 \mathrm{M})$ solution until the $\mathrm{pH}$ reached 9.5 . It was then aged for $24 \mathrm{~h}$. The obtained precipitate was centrifuged, washed with deionized water (DW), and then lyophilized. 


\subsection{Preparation of ZOE-LDH Hybrid}

To encapsulate $\mathrm{ZOE}$ by $\mathrm{LDH}$, pristine $\mathrm{MgFe}-\mathrm{CO}_{3}-\mathrm{LDH}$ was first calcined at $400{ }^{\circ} \mathrm{C}$ for $9 \mathrm{~h}$ in a muffle furnace to obtain MgFe-layered double oxide (MgFe-LDO). ZOE was then incorporated with $\mathrm{LDH}$ to prepare hybrid ZOE-LDH by reconstruction route. Typically, $0.741 \mathrm{~g}$ of ZOE was dissolved in $100 \mathrm{~mL}$ of $10 \%$ dimethyl sulfoxide (DMSO) solution and then $1.742 \mathrm{~g}$ of MgFe-LDO powder was dispersed in ZOE solution. The suspension was stirred for $24 \mathrm{~h}$ under $\mathrm{N}_{2}$ gas condition. A powder, as the final product, was obtained by lyophilization of centrifuged and washed precipitate.

\subsection{Characterization}

Powder X-ray diffraction (PXRD) patterns of ZOE, MgFe-LDH, MgFe-LDO, and ZOE-LDH hybrid were investigated using Ultima IV (Rigaku, Tokyo, Japan) with $\mathrm{Cu} \mathrm{K}_{\alpha}$ radiation $(\lambda=1.5406 \AA$ ). Diffraction patterns were obtained in the $2 \theta$ range from 5 to $80^{\circ}$ with a scanning rate of $5^{\circ} / \mathrm{min}$. The intact structure of ZOE in the ZOE-LDH hybrid was identified by Fourier transform infrared spectroscopy (FT-IR, Frontier MIR/FIR spectrometer, Perkin Elmer, Waltham, MA, USA) with a scanning range from 4000 to $400 \mathrm{~cm}^{-1}$ using the conventional $\mathrm{KBr}$ method. Particle morphologies of ZOE and its hybrid were examined by field emission-scanning electron microscopy (FE-SEM, JSM-7100F, JEOL-USA Inc., Peabody, MA, USA)). The hydrodynamic radius and surface charge of pristine LDH and ZOE-LDH hybrid were investigated by dynamic light scattering (DLS) and zeta-potential using an ELSZ-1000 analyzer (Otsuka, Kyoto, Japan). For zeta-potential and DLS, $1 \mathrm{mg}$ of each powder was dispersed in $10 \mathrm{~mL}$ of DW. The content of ZOE in ZOE-LDH hybrid was evaluated by measuring the mass of the initial and remnant of ZOE in the reaction vessel. Thermogravimetry analysis (TG) (SDT Q600, TA Instruments, New Castle, DE, USA) of ZOE and ZOE-LDH hybrid was carried out with a heating rate of $10{ }^{\circ} \mathrm{C} / \mathrm{min}$ under air gas condition from 30 to $1000^{\circ} \mathrm{C}$. The chemical formula of ZOE-LDH hybrid was determined based on the ZOE content and the TG result of the ZOE-LDH hybrid.

\subsection{Radical Scavenging Activity}

To evaluate the ability of LDH in preserving the antioxidant activity of the payload, DPPH assay was carried out for both ZOE and the ZOE-LDH hybrid before and after treatment with ultrasound and microwave irradiation. ZOE solution and ZOE-LDH suspension were prepared in $10 \%$ DMSO to obtain a concentration of $1 \mathrm{mg} / \mathrm{mL}$. The prepared solution and suspension were then exposed to harsh conditions using microwave for 0,1 , and $3 \mathrm{~min}$, and ultrasound for 0,5 , and $30 \mathrm{~min}$, respectively. Both samples were then diluted to have ZOE concentrations of 1000, 500, 250, 125, 62.5, 31.25, 15.623, 7.8123, and $3.906 \mathrm{ppm}$. For comparison, $\mathrm{MgFe}-\mathrm{LDH}$ suspension was treated with ultrasound or microwave irradiation and diluted so that the concentration of the inorganic part was the same as that of the ZOE-LDH suspension. For DPPH assay, $200 \mu \mathrm{L}$ of each sample was mixed with $800 \mu \mathrm{L}$ of DPPH solution $\left(3.8 \times 10^{-4} \mathrm{M}\right.$ of DPPH in $\left.80 \% \mathrm{MeOH}\right)$. As a negative control, $200 \mu \mathrm{L}$ of $80 \% \mathrm{MeOH}$ without sample was mixed with $800 \mu \mathrm{L}$ of DPPH solution. A sample blank was prepared by replacing DPPH solution with $80 \% \mathrm{MeOH}$ for each mixture. The mixture was agitated for $30 \mathrm{~min}$ at room temperature under dark conditions. The absorbance of each sample was then measured at wavelength of $517 \mathrm{~nm}$. The antioxidant activity was calculated using the equation below:

Antioxidant activity $(\%)=[$ control absorbance $-($ sample absorbance - blank absorbance)/control absorbance] $\times 100$

\section{Results and Discussion}

To investigate the crystal structures of ZOE, MgFe-LDH, MgFe-LDO, and ZOE-LDH hybrid, X-ray diffraction (XRD) patterns of powdered samples were obtained. The XRD pattern of $\mathrm{MgFe}-\mathrm{CO}_{3}-\mathrm{LDH}$ showed characteristic peaks of pyroaurite (JCPDS. No 14-0293) at 11.04, 23.15, 33.73, 37.86, 59.43, and $60.81^{\circ}$ for (003), (006), (012), (015), (110), and (113), respectively as shown in Figure 1b [27]. After 
calcination, pyroaurite phase of $\mathrm{MgFe}-\mathrm{CO}_{3}-\mathrm{LDH}$ transformed to periclase (MgO; JCPDS. No. 45-0946) with peak position at $35.36,42.68$, and $62.11^{\circ}$ corresponding to (111), (200), and (220) reflections, respectively, as shown in Figure 1c [28]. ZOE itself was found to be amorphous, exhibiting a broad pattern between 15 and $20^{\circ}$, possibly due to random assembly among carbohydrate residues in ZOE moiety as shown in Figure 1a. In the XRD pattern of the ZOE-LDH hybrid, (003), (012), (110), and (113) peaks corresponding to pyroaurite were observed, indicating recovery of the original LDH phase upon reconstruction as shown in Figure 1d. The peak position of (003) in ZOE-LDH hybrid was the same as that in pristine $\mathrm{LDH}$, suggesting that the relatively large molecule in $\mathrm{ZOE}$ was not incorporated into the interlayer space of LDH. After hybridization, crystallite size along (003) and (110) plane of LDH decreased from 7.1 and $11.3 \mathrm{~nm}$ to 4.4 and $6.1 \mathrm{~nm}$, respectively (calculated by Scherrer's equation) [29]. The reduction of crystallinity was attributed to partial disorder and reorganization of the LDH lattice during the reconstruction process. Similar phenomena have been reported in the reconstruction of LDH [30]. Periclase peak of LDO was observed in the ZOE-LDH hybrid, showing crystallite size (along (200) plane of periclase) reduction from 7.0 to $5.4 \mathrm{~nm}$. Why LDO did not fully recover the LDH structure was unclear. Large biomolecules in $\mathrm{ZOE}$ might have disturbed the hydration of $\mathrm{MgO}$ to $\mathrm{MgFe}-\mathrm{LDH}$. Reduction in the crystalline size of LDO after reconstruction suggested that the phase transformation from LDO to LDH was hindered during the process. This might be due to the action of various organic moiety in ZOE. Although we could not obtain pure LDH phase in the ZOE-LDH hybrid, the existence of the LDO phase was not disadvantageous in this study. Periclase is known to have several advantages in biological and environmental applications, such as limited solubility in water, inherent biocompatibility, environmental friendliness, high melting point, and low heat capacity [31,32]. Thus, the existence of periclase in the hybrid can enhance the protection ability of inorganic shell along with the physicochemical stability of LDH $[33,34]$.

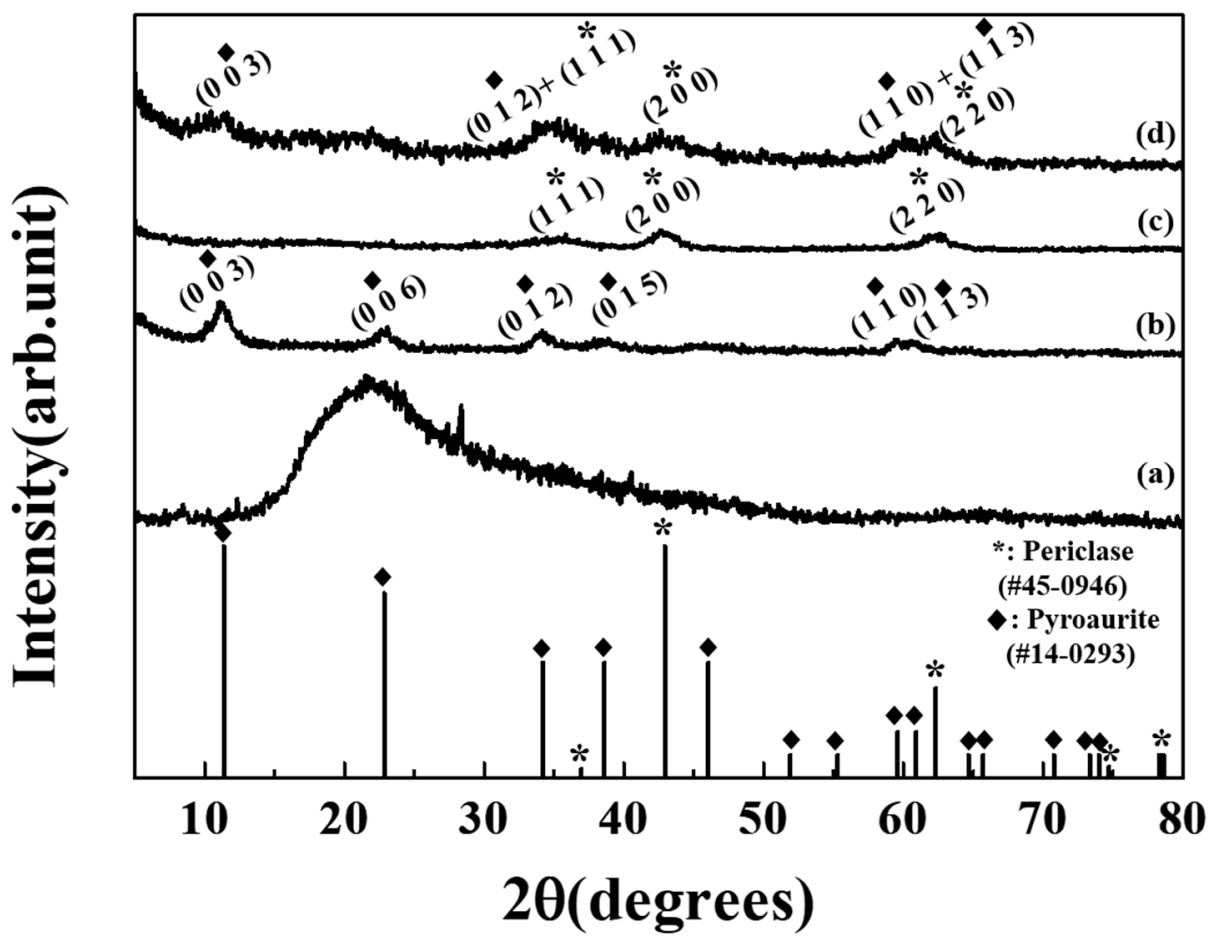

Figure 1. X-ray diffraction patterns of (a) Zingiber officinale extract (ZOE), (b) MgFe-LDH (layered double hydroxide), (c) MgFe-LDO (layered double oxide), and (d) ZOE-LDH hybrid.

To identify incorporated moieties in the ZOE-LDH hybrid, FT-IR analyses of ZOE, pristine $\mathrm{MgFe}-\mathrm{LDH}$, and ZOE-LDH were carried out. The FT-IR spectrum of MgFe-LDH showed a characteristic stretching peak of M-O for LDH at $575.6 \mathrm{~cm}^{-1}$, as shown in Figure 2a $[35,36]$. In the IR 
spectrum of ZOE, C-O-C stretching of dialkyl ether, $\mathrm{C}-\mathrm{O}-\mathrm{C}$ stretching of lignin, and $\mathrm{C}-\mathrm{C}$ stretching of cellulose were observed at 1152, 1079, and $1024 \mathrm{~cm}^{-1}$, respectively, as shown in Figure 2c [37,38]. After hybridization, $\mathrm{M}-\mathrm{O}$ stretching of $\mathrm{LDH}$ and $\mathrm{C}=\mathrm{O}, \mathrm{C}-\mathrm{O}-\mathrm{C}$, and $\mathrm{C}-\mathrm{O}$ stretching of $\mathrm{ZOE}$ co-existed in the IR spectrum of the ZOE-LDH hybrid, as shown in Figure $2 \mathrm{~b}$. These results demonstrated that the intact structure of ZOE moieties was preserved safely in ZOE-LDH hybrid after the reconstruction reaction.
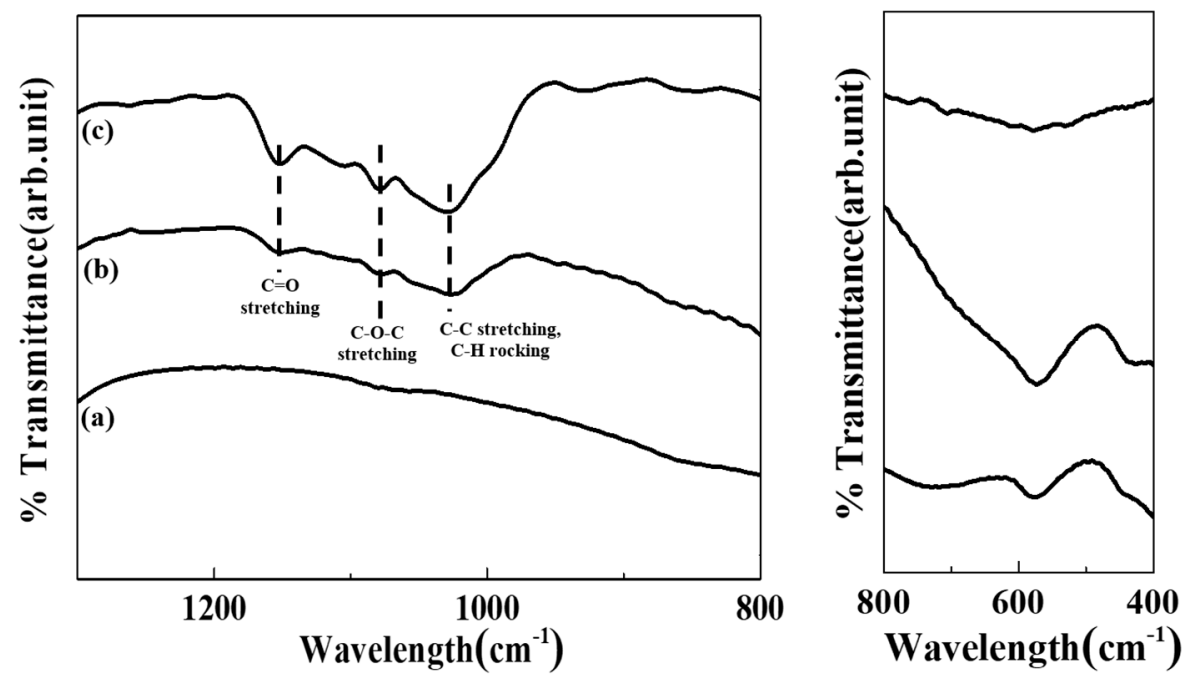

Figure 2. Fourier transform infrared spectra of (a) $\mathrm{MgFe}-\mathrm{LDH}$, (b) Zingiber officinale extract-layered double hydroxide (ZOE-LDH) hybrid and (c) ZOE.

The morphology of ZOE-LDH hybrid was investigated using SEM. The image in Figure 3a shows the large and glassy particles of ZOE. Taking into account the amorphous nature of ZOE as shown in Figure 1a, the glassy morphology of ZOE might be attributed to the intermolecular interaction among organic moiety in the natural extract. In the SEM image of the ZOE-LDH hybrid, two kinds of characteristic morphology, house-of-card and coin-like shape, both with agglomerated phase of $79.0 \pm 8.84 \mathrm{~nm}$-sized primary particles, were observed as shown in Figure 3c. They might be attributed to reconstructed LDH [39] and LDO [40], respectively, as shown in Figure 3b. The house-of-card morphology of reconstructed LDH was attributed to the increase of face-to-edge interaction when LDH underwent disorder and reorientation during the reconstruction process. The house-of-card structure can provide extract moiety with interparticle space for protective encapsulation. It was worthy to note that glassy-surface morphology was not observed in the SEM image of the ZOE-LDH hybrid, suggesting that the intermolecular interaction in ZOE was successfully prevented by LDH/LDO moiety and that the ZOE was safely incorporated in the inorganic lattice.
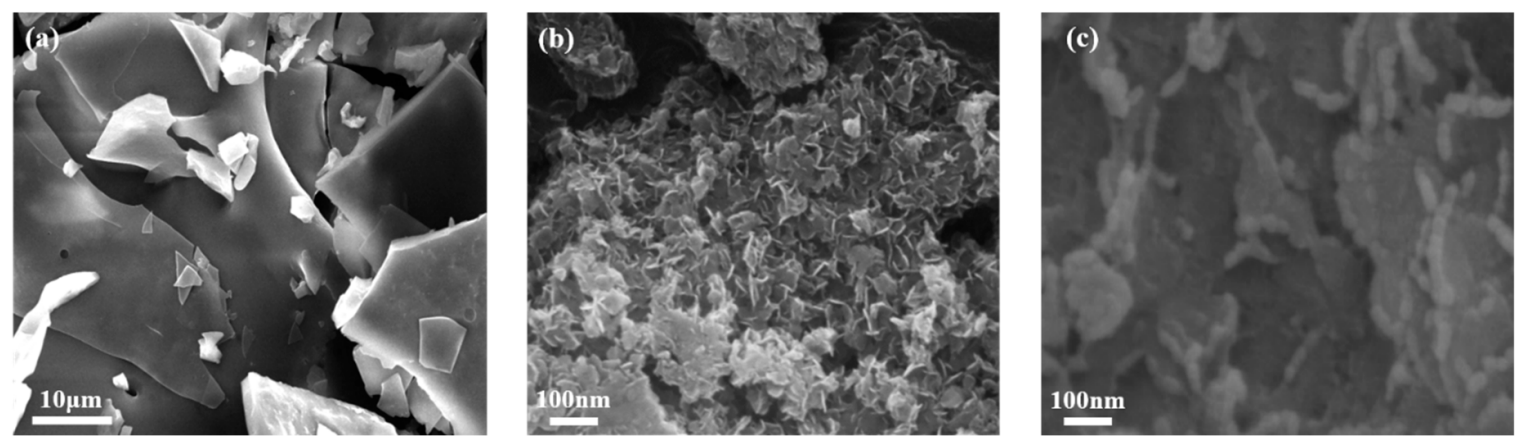

Figure 3. Scanning electron microscope image of (a) Zingiber officinale extract (ZOE), (b) Zingiber officinale extract-layered double hydroxide (ZOE-LDH) hybrid, and (c) magnified ZOE-LDH hybrid. 
To confirm the location of the organic moiety of ZOE in the hybrid, surface charges of pristine $\mathrm{LDH}, \mathrm{ZOE}$, and ZOE-LDH hybrid were examined by measuring their zeta-potentials. As reported previously, the zeta-potential value of pristine $\mathrm{MgFe}-\mathrm{LDH}$ was fairly positive at $13.30 \pm 1.85 \mathrm{mV}$ (pH 6.97), as shown in Figure 4 as a solid line [41]. On the other hand, ZOE had a negative zeta-potential of $-24.12 \pm 1.09 \mathrm{mV}$ (pH 7.01), possibly due to abundant $\delta$-moiety and anionic sites carbohydrate, lipid, polyphenol, and others, as shown in Figure 4 as a dashed line [42]. After encapsulation of ZOE with $\mathrm{LDH}$, the zeta-potential was found to be $4.53 \pm 0.76 \mathrm{mV}$ (pH 7.06), as shown in Figure 4 as open circles, which was between zeta-potential values of $\mathrm{ZOE}$ and LDH but leaned towards that of LDH. If ZOE exhibited an outer surface of LDH after hybridization, the zeta-potential of ZOE-LDH would be more biased towards ZOE. As zeta-potential of ZOE-LDH still resided in the positive region, it suggested that ZOE was encapsulated in the interparticle space of $\mathrm{LDH}$, rather than attached on the surface of $\mathrm{LDH}$. This result was similar to our previous result that Angelica gigas Nakai extract incorporated in LDH hybrid showed positive zeta-potential [43]. Based on XRD patterns, IR spectra, SEM images, and zeta-potential, we could conclude that MgFe-LDH lost its lamellar structure upon calcination, and the original layered structure was partially recovered to develop the interparticle space of LDH with intact ZOE moiety.

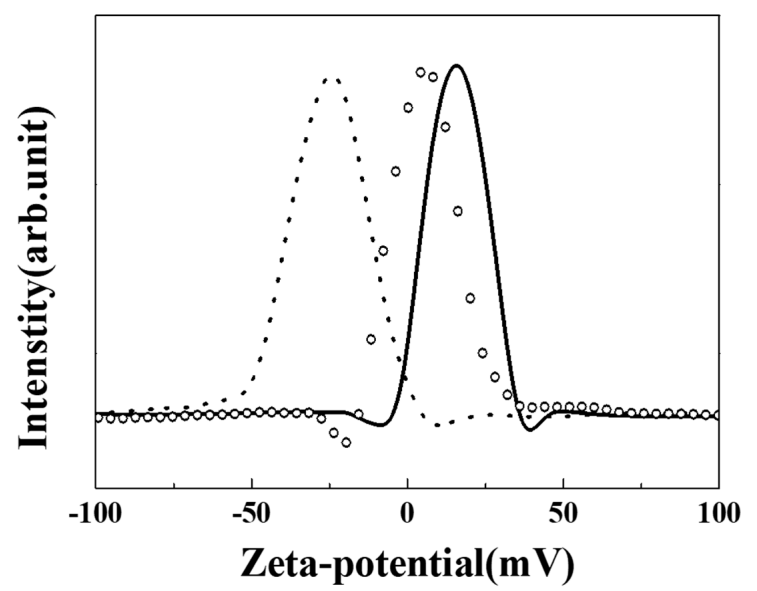

Figure 4. Zeta-potential graphs of: $\mathrm{MgFe}-\mathrm{LDH}$ (layered double hydroxide)-solid line, Zingiber officinale extract (ZOE)-dashed line, and ZOE-LDH hybrid-open circles.

In this regard, we expect that ZOE in the ZOE-LDH hybrid can be well protected in the interparticle cavity of LDH from external harsh conditions and that its biological function, such as antioxidant properties could be preserved in the hybrid, as shown in Scheme 1.

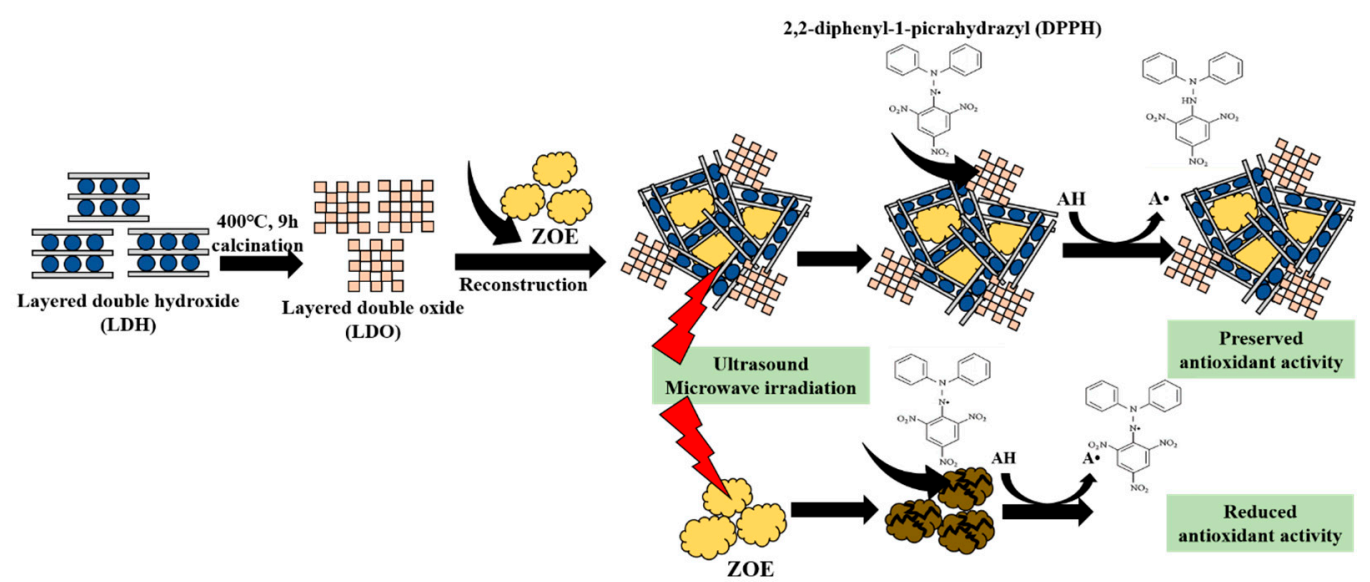

Scheme 1. Schematic diagram to preserve antioxidant activity of Zingiber officinale extract (ZOE) by layered double hydroxide (LDH) from external harsh conditions. 
The TG curves and corresponding first derivatives of ZOE and the ZOE-LDH hybrid are shown in Figure 5. Temperature-dependent weight loss of ZOE occurred in the wide temperature range between 25 and $1000{ }^{\circ} \mathrm{C}$ with a corresponding weight loss of $88.32 \%$, as shown in Figure 5(Aa). Detailed analyses with the first derivative of the TG curve revealed that this range consisted of steps at 154.6, 195.4, and $293.8^{\circ} \mathrm{C}$ as shown in Figure 5(Ba). ZOE-LDH showed two-step weight loss from 25 to $154.2^{\circ} \mathrm{C}$ and 154.2 to $647.5{ }^{\circ} \mathrm{C}$ with corresponding weight loss of $10.0 \%$ and $15.40 \%$, as shown in Figure $5(\mathrm{Ab})$. The first step was attributed to the dehydration of surface or interlayer absorbed water [44], while the second step could be due to thermal decomposition of the encapsulated ZOE moiety and dehydroxylation of the LDH lattice together [45]. Similar to thermal decomposition of ZOE, the ZOE-LDH hybrid showed three steps of decomposition at $226.3,338.7$, and $436.3^{\circ} \mathrm{C}$, as shown in Figure $5(\mathrm{Bb})$. Although it was not clear whether all three steps were attributed to the thermal decomposition of ZOE moiety, it was worthy to note that the decomposition temperature points were higher than those of the major decomposition of ZOE alone as shown when comparing Figure 5(Ba) with Figure 5(Bb). We could, therefore, conclude that ZOE in the hybrid was protected by the LDH/LDO particle to acquire thermal stability. TG data and weight differences in extract quantification suggested that the chemical formula of the $\mathrm{ZOE}-\mathrm{LDH}$ hybrid was $\left.\left(\mathrm{Mg}_{2} \mathrm{FeO}_{3.5}\right)\left[\mathrm{Mg}_{2} \mathrm{Fe}(\mathrm{OH})_{6}\left(\mathrm{CO}_{3}\right)_{0.5}\right]_{0.77} \cdot \mathrm{ZOE}\right) \cdot 2.34 \mathrm{H}_{2} \mathrm{O}$, where $\mathrm{ZOE}$ content was $9.68 \mathrm{wt} / \mathrm{wt} \%$.

(A)
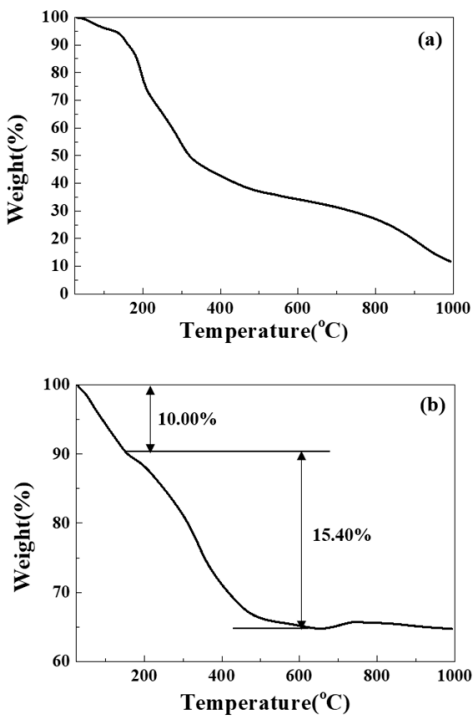

(B)
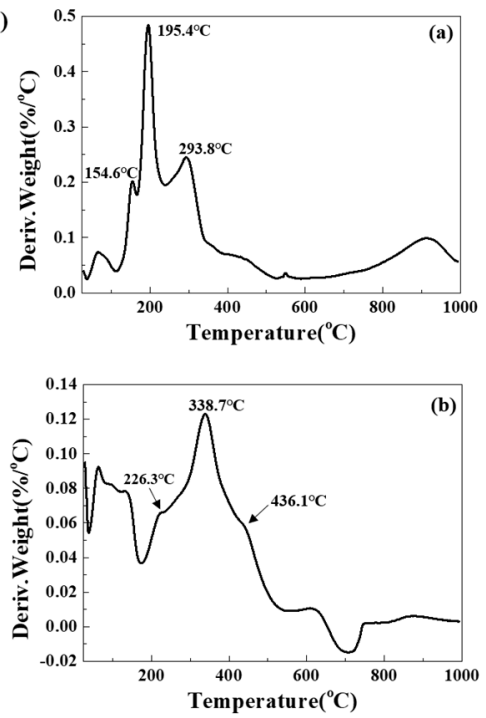

Figure 5. (A) Thermogravimetry (TG) curves and (B) corresponding first derivative patterns for (a) Zingiber officinale extract (ZOE) and (b) ZOE-LDH (layered double hydroxide) hybrid.

To evaluate the antioxidant activities of the ZOE and ZOE-LDH hybrid, a radical scavenging assay was carried out before and after ultrasound and microwave irradiation on ZOE and ZOE-LDH. The concentration-dependent inhibition curve of ZOE shifted to the right side after ultrasound and microwave irradiation, as shown in Figure 6A, meaning reduced radical scavenging activity of ZOE. On the other hand, the inhibition curve of ZOE-LDH showed enhanced antioxidant activity, as shown in Figure 6B,C. The enhancement of antioxidant activity of ZOE-LDH after ultrasound and microwave irradiation occurs only in high ZOE concentration. The inhibition curve of ZOE-LDH resembles the Hill-Langmuir equation which usually reflects ligand binding to macromolecules in biochemistry and pharmacology. In the Hill-Langmuir equation, $\mathrm{K}_{\mathrm{A}}$ indicates the standard concentration for representing activity [46]. $\mathrm{K}_{\mathrm{A}}$ values of ultrasound $(5 \mathrm{~min}$ ) and microwave (1 min)-treated ZOE-LDH were 86.36 and 84.96 ppm, respectively. This result revealed ZOE-LDH did not show antioxidant activity at a concentration lower than $86.36 \mathrm{ppm}$, therefore, there was no increasing antioxidant activity at a lower $\mathrm{ZOE}$ concentration. On the other hand, since antioxidant activity begins to appear at high ZOE concentration, their antioxidant activity increased through the protecting effect by inorganic 
LDH and LDO. Detailed results of antioxidant activities of ZOE and the ZOE-LDH hybrid are shown in Table $1 . \mathrm{IC}_{50}$ values (the concentration needed to inhibit $50 \%$ of antioxidant activity) of $\mathrm{ZOE}$ and the ZOE-LDH hybrid for radical scavenging activity were determined to be $201.81 \pm 13.59$ and $349.17 \pm 47.50 \mathrm{ppm}$, respectively. As ZOE concentration in ZOE itself and ZOE-LDH was the same, the maximum $\mathrm{IC}_{50}$ value of the ZOE-LDH hybrid must be $201.81 \pm 13.59 \mathrm{ppm}$. However, the ZOE-LDH hybrid showed an increased $\mathrm{IC}_{50}$ value, indicating reduced antioxidant activity. The lower antioxidant activity of the ZOE-LDH hybrid was due to captured ZOE moieties in the interparticle pores of $\mathrm{LDH}$ and LDO, which could not interact with the DPPH radical. After ultrasound and microwave irradiation, ZOE presented increased $\mathrm{IC}_{50}$ value as $1003.29 \pm 79.82 \mathrm{ppm}$ for ultrasound irradiation and $353.73 \pm 29.93$ ppm for microwave irradiation, revealing decreased antioxidant activity. On the contrary, radical scavenging activity of $\mathrm{ZOE}-\mathrm{LDH}$ was increased upon ultrasound and microwave irradiation, showing decreased $\mathrm{IC}_{50}$ values as $270.65 \pm 28.78 \mathrm{ppm}$ (for $5 \mathrm{~min}$ ) and $259.36 \pm 25.42 \mathrm{ppm}$ (for $1 \mathrm{~min}$ ), respectively. The enhanced radical scavenging activity might be due to the release of $\mathrm{ZOE}$ moieties in the interparticle cavity of LDH and LDO after ultrasound and microwave irradiation. Although the antioxidant activity of ZOE-LDH after ultrasound and microwave irradiation was enhanced, the $\mathrm{IC}_{50}$ value was still higher than the $\mathrm{IC}_{50}$ value of non-treated $\mathrm{ZOE}$ (maximum radical scavenging activity). This is due to partially remained ZOE in the interparticle cavity of LDH and LDO. Moreover, upon increasing irradiation time, the $\mathrm{IC}_{50}$ values of $\mathrm{ZOE}-\mathrm{LDH}$ revealed $252.46 \pm 12.47 \mathrm{ppm}$ for ultrasound (30 $\mathrm{min}$ ) and $231.82 \pm 19.00 \mathrm{ppm}$ for microwave $(3 \mathrm{~min})$, which was the same values with shorter irradiation time as the $99 \%$ confidence intervals calculated by the Student's $t$-test. This result was attributed to insulation, radical blocking, and microwave absorption properties of LDH and LDO. Thus, incorporated ZOE moieties were protected when temperature was increased and $\mathrm{OH}$ radical was formed by ultrasound and microwave irradiation. From these results, we concluded that ZOE was effectively protected by LDH and LDO, thus having suitable physicochemical properties.

(A)

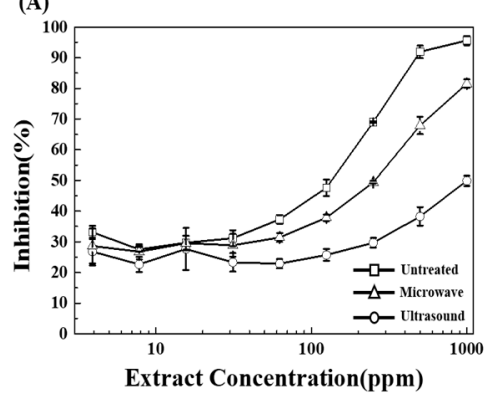

(B)

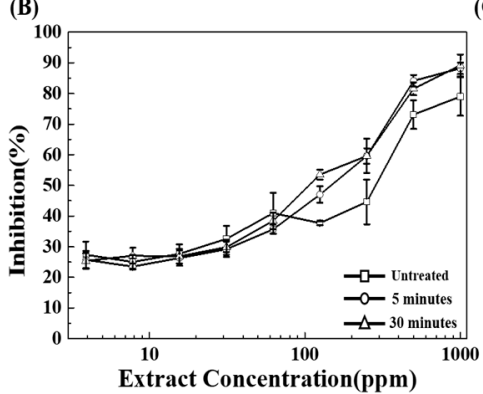

(C)



Figure 6. Radical scavenging activity results of (A) Zingiber officinale extract (ZOE) in untreated, ultrasound for $30 \mathrm{~min}$ and microwave irradiation for $1 \mathrm{~min}$, ZOE-LDH hybrid untreated and irradiation of (B) ultrasound and (C) microwave.

Table 1. $\mathrm{IC}_{50}$ values of radical scavenging of Zingiber officinale extract (ZOE) and ZOE-LDH (layered double hydroxide) hybrid.

\begin{tabular}{ccc}
\hline \multirow{2}{*}{ Irradiated Conditions } & \multicolumn{2}{c}{ IC $_{\mathbf{5 0}}$ (ppm) } \\
\cline { 2 - 3 } & ZOE & ZOE-LDH Hybrid \\
\hline Untreated & $201.81 \pm 13.59$ & $349.17 \pm 47.50$ \\
Ultrasound for 5 min & - & $270.65 \pm 28.78^{\mathrm{a}}$ \\
Ultrasound for 30 min & $1003.29 \pm 79.82$ & $252.46 \pm 12.47^{\mathrm{a}}$ \\
Microwave irradiation for 1 min & $353.73 \pm 29.93$ & $259.36 \pm 25.42^{\mathrm{b}}$ \\
Microwave irradiation for 3 min & - & $231.82 \pm 19.00^{\mathrm{b}}$ \\
\hline
\end{tabular}

Ultrasonic: $500 \mathrm{~W}, 20 \mathrm{KHz}$, Microwave: $700 \mathrm{~W}, 2.45 \mathrm{GHz}$, a and b represent the same value with confidence intervals of $99 \%$ obtained by Student's $t$-test. 


\section{Conclusions}

We prepared ZOE-incorporated LDH using a reconstruction process to protect ZOE moieties from harsh conditions. XRD patterns and FT-IR spectra data confirmed that ZOE moieties were incorporated into LDH and LDO due to partial reconstruction of LDO, which has insulation and microwave absorption properties. According to SEM, zeta-potential, and dynamic light scattering analyses, ZOE was incorporated into the interparticle pores of LDH and LDO formed by a few particles. TGA/DTG analysis and measurement of ZOE content revealed that $9.68 \%$ of ZOE moieties in the ZOE-LDH hybrid were protected by LDH and LDO. DPPH assay results indicated that antioxidant activity of ZOE was decreased after ultrasound and microwave irradiation. On the other hand, the radical scavenging activity of $Z \mathrm{OE}-\mathrm{LDH}$ was increased due to released $\mathrm{ZOE}$ moieties which protected $\mathrm{ZOE}$ from $\mathrm{OH}$ radical and high temperature because $\mathrm{ZOE}$ moieties were found in the interparticle pores of LDH and LDO during ultrasound and microwave irradiation. These results suggest that the antioxidant activity of ZOE can be effectively preserved by hybridization with LDH using a reconstruction process.

Author Contributions: H.-J.K. prepared and drafted the manuscript; S.-B.L. prepared and analyzed samples; J.-M.O. prepared the manuscript and designed the study; A.-J.C. prepared ZOE and designed the study. All authors discussed and approved the final manuscript.

Funding: This work was supported by the Industrial Core Technology Development Program (No. 10063291, Development of multifunctional porous ceramic convergence materials for high-quality keeping freshness packaging) funded by the Ministry of Trade, Industry \& Energy (MOTIE, Korea) and by the National Research Foundation of Korea (NRF) grant funded by the Korea government (MIST) (No. 2017R1A2B40006352).

Conflicts of Interest: The authors declare no conflict of interest.

\section{References}

1. Altemimi, A.; Lakhssassi, N.; Baharlouei, A.; Watson, D.G.; Lightfoot, D.A. Phytochemicals: Extraction, Isolation, and Identification of Bioactive Compounds from Plant Extracts. Plants 2017, 6, 42. [CrossRef] [PubMed]

2. Kähkönen, M.P.; Hopia, A.I.; Vuorela, H.J.; Rauha, J.-P.; Pihlaja, K.; Kujala, T.S.; Heinonen, M. Antioxidant Activity of Plant Extracts Containing Phenolic Compounds. J. Agric. Food Chem. 1999, 47, 3954-3962. [CrossRef] [PubMed]

3. Proestos, C.; Sereli, D.; Komaitis, M. Determination of phenolic compounds in aromatic plants by RP-HPLC and GC-MS. Food Chem. 2006, 95, 44-52. [CrossRef]

4. Dai, J.; Mumper, R.J. Plant Phenolics: Extraction, Analysis and Their Antioxidant and Anticancer Properties. Molecules 2010, 15, 7313-7352. [CrossRef] [PubMed]

5. Morakinyo, A.; Adeniyi, O.; Arikawe, A. Effects of Zingiber Officinale on Reproductive Functions in the Male Rat. Afr. J. Biomed. Res. 2010, 11, 329-334. [CrossRef]

6. Stoilova, I.; Krastanov, A.; Stoyanova, A.; Denev, P.; Gargova, S. Antioxidant activity of a ginger extract (Zingiber officinale). Food Chem. 2007, 102, 764-770. [CrossRef]

7. El-Ghorab, A.H.; Nauman, M.; Anjum, F.M.; Hussain, S.; Nadeem, M. A Comparative Study on Chemical Composition and Antioxidant Activity of Ginger (Zingiber officinale) and Cumin (Cuminum cyminum). J. Agric. Food Chem. 2010, 58, 8231-8237. [CrossRef]

8. Dugasani, S.; Pichika, M.R.; Nadarajah, V.D.; Balijepalli, M.K.; Tandra, S.; Korlakunta, J.N. Comparative antioxidant and anti-inflammatory effects of [6]-gingerol, [8]-gingerol, [10]-gingerol and [6]-shogaol. J. Ethnopharmacol. 2010, 127, 515-520. [CrossRef]

9. Fazaeli, M.; Yousefi, S.; Emam-Djomeh, Z. Investigation on the effects of microwave and conventional heating methods on the phytochemicals of pomegranate (Punica granatum L.) and black mulberry juices. Food Res. Int. 2013, 50, 568-573. [CrossRef]

10. Fang, X.; Mark, G.; Von Sonntag, C. OH radical formation by ultrasound in aqueous solutions Part I: The chemistry underlying the terephthalate dosimeter. Ultrason. Sonochem. 1996, 3, 57-63. [CrossRef]

11. Bremner, D.H.; Burgess, A.E.; Chand, R. The Chemistry of Ultrasonic Degradation of Organic Compounds. Curr. Org. Chem. 2011, 15, 168-177. [CrossRef] 
12. Sun, J.; Mei, Z.; Tang, Y.; Ding, L.; Jiang, G.; Zhang, C.; Sun, A.; Bai, W. Stability, Antioxidant Capacity and Degradation Kinetics of Pelargonidin-3-glucoside Exposed to Ultrasound Power at Low Temperature. Molecules 2016, 21, 1109. [CrossRef] [PubMed]

13. Nakilcioglu-Taş, E.; Ötleş, S. Degradation kinetics of bioactive compounds and antioxidant capacity of Brussels sprouts during microwave processing. Int. J. Food Prop. 2017, 20, S2798-S2809. [CrossRef]

14. Haq, N.; Muhammad Aslam, S.; Aziz ur Rehman, A.; Sidra Tul, M.; Saima, M. Phytochemical Composition and Antioxidant Potential of Oven Heated and Microwave Treated Ginger (Zingiber officinale Roscoe). Free Radic. Antioxid. 2018, 8. [CrossRef]

15. Abbas, K.A.; Saleh, A.M.; Saeed, M.; MohdAzhan, N. The recent advances in the nanotechnology and its applications in food processing: A review. J. Food Agric. Environ. 2009, 7, 14-17.

16. LeMarchand, C.; Gref, R.; Couvreur, P.; Patrick, C. Polysaccharide-decorated nanoparticles. Eur. J. Pharm. Biopharm. 2004, 58, 327-341. [CrossRef] [PubMed]

17. Tarhini, M.; Greige-Gerges, H.; Elaissari, A. Protein-based nanoparticles: From preparation to encapsulation of active molecules. Int. J. Pharm. 2017, 522, 172-197. [CrossRef]

18. Choy, J.-H.; Jung, J.-S.; Oh, J.-M.; Park, M.; Jeong, J.; Kang, Y.-K.; Han, O.-J. Layered double hydroxide as an efficient drug reservoir for folate derivatives. Biomaterials 2004, 25, 3059-3064. [CrossRef]

19. Wei, M.; Shi, S.; Wang, J.; Li, Y.; Duan, X. Studies on the intercalation of naproxen into layered double hydroxide and its thermal decomposition by in situ FT-IR and in situ HT-XRD. J. Solid State Chem. 2004, 177, 2534-2541. [CrossRef]

20. Gao, X.; Chen, L.; Xie, J.; Yin, Y.; Chang, T.; Duan, Y.; Jiang, N. In vitro controlled release of vitamin C from Ca/Al layered double hydroxide drug delivery system. Mater. Sci. Eng. C 2014, 39, 56-60. [CrossRef]

21. Rives, V. Layered Double Hydroxides: Present and Future; Nova Publishers: Hauppauge, NY, USA, 2001.

22. Gao, Y.; Wu, J.; Wang, Q.; Wilkie, C.A.; O'Hare, D. Flame retardant polymer/layered double hydroxide nanocomposites. J. Mater. Chem. A 2014, 2, 10996. [CrossRef]

23. Ramaraj, B.; Yoon, K.R. Thermal and physicomechanical properties of ethylene-vinyl acetate copolymer and layered double hydroxide composites. J. Appl. Polym. Sci. 2008, 108, 4090-4095. [CrossRef]

24. Oh, J.-M.; Kwak, S.-Y.; Choy, J.-H. Intracrystalline structure of DNA molecules stabilized in the layered double hydroxide. J. Phys. Chem. Solids 2006, 67, 1028-1031. [CrossRef]

25. Choy, J.-H.; Son, Y.-H. Intercalation of vitamer into LDH and their controlled release properties. Bull. Korean Chem. Soc. 2004, 25, 122-126.

26. Kim, B.-K.; Gwak, G.-H.; Okada, T.; Oh, J.-M. Effect of particle size and local disorder on specific surface area of layered double hydroxides upon calcination-reconstruction. J. Solid State Chem. 2018, 263, 60-64. [CrossRef]

27. Brown, G. Crystal Structures of Clay Minerals and Their X-ray Identification; The Mineralogical Society of Great Britain and Ireland: London, UK, 1982; Volume 5.

28. Pallon, L.K.H.; Olsson, R.T.; Pourrahimi, A.M.; Hedenqvist, M.S.; Hoang, A.T.; Gubanski, S.; Gedde, U.W.; Liu, D. Formation and the structure of freeze-dried $\mathrm{MgO}$ nanoparticle foams and their electrical behaviour in polyethylene. J. Mater. Chem. A 2015, 3, 7523-7534. [CrossRef]

29. Cullity, B.D.; Stock, S.R. Elements of X-ray Diffraction; Prentice Hall: Upper Saddle River, NJ, USA, 2001; Volume 3.

30. Kang, H.; Kim, H.-J.; Yang, J.-H.; Kim, T.-H.; Choi, G.; Paek, S.-M.; Choi, A.-J.; Choy, J.-H.; Oh, J.-M. Intracrystalline structure and release pattern of ferulic acid intercalated into layered double hydroxide through various synthesis routes. Appl. Clay Sci. 2015, 112, 32-39. [CrossRef]

31. Devi, R.R.; Umlong, I.M.; Raul, P.K.; Das, B.; Banerjee, S.; Singh, L. Defluoridation of water using nano-magnesium oxide. J. Exp. Nanosci. 2014, 9, 512-524. [CrossRef]

32. Srivastava, V.; Sharma, Y.C.; Sillanpää, M. Green synthesis of magnesium oxide nanoflower and its application for the removal of divalent metallic species from synthetic wastewater. Ceram. Int. 2015, 41, 6702-6709. [CrossRef]

33. Benito, P.; Labajos, F.; Mafra, L.; Rocha, J.; Rives, V. Carboxylate-intercalated layered double hydroxides aged under microwave-hydrothermal treatment. J. Solid State Chem. 2009, 182, 18-26. [CrossRef]

34. Du, B.; Guo, Z.; Fang, Z. Effects of organo-clay and sodium dodecyl sulfonate intercalated layered double hydroxide on thermal and flame behaviour of intumescent flame retarded polypropylene. Polym. Degrad. Stab. 2009, 94, 1979-1985. [CrossRef] 
35. Ding, Y.; Gui, Z.; Zhu, J.; Hu, Y.; Wang, Z. Exfoliated poly(methyl methacrylate)/MgFe-layered double hydroxide nanocomposites with small inorganic loading and enhanced properties. Mater. Res. Bull. 2008, 43, 3212-3220. [CrossRef]

36. Li, F.; Liu, J.; Evans, D.G.; Duan, X. Stoichiometric Synthesis of Pure $\mathrm{MFe}_{2} \mathrm{O}_{4}(\mathrm{M}=\mathrm{Mg}$, Co, and Ni) Spinel Ferrites from Tailored Layered Double Hydroxide (Hydrotalcite-Like) Precursors. Chem. Mater. 2004, 16, 1597-1602. [CrossRef]

37. Zhao, X.; Zhu, H.; Chen, J.; Ao, Q. FTIR, XRD and SEM Analysis of Ginger Powders with Different Size. J. Food Process. Preserv. 2015, 39, 2017-2026. [CrossRef]

38. Devi, A.; Das, V.K.; Deka, D. Ginger extract as a nature based robust additive and its influence on the oxidation stability of biodiesel synthesized from non-edible oil. Fuel 2017, 187, 306-314. [CrossRef]

39. Kim, T.-H.; Lee, G.J.; Kang, J.-H.; Kim, H.-J.; Kim, T.-I.; Oh, J.-M. Anticancer Drug-Incorporated Layered Double Hydroxide Nanohybrids and Their Enhanced Anticancer Therapeutic Efficacy in Combination Cancer Treatment. BioMed Res. Int. 2014, 2014, 1-11. [CrossRef] [PubMed]

40. Peng, F.; Luo, T.; Yuan, Y. Controllable synthesis of Mg-Fe layered double hydroxide nanoplates with specific $\mathrm{Mg} / \mathrm{Fe}$ ratios and their effect on adsorption of As(v) from water. New J. Chem. 2014, 38, 4427. [CrossRef]

41. Kang, H.; Kim, M.; Feng, Q.; Lin, S.; Wei, K.; Li, R.; Choi, C.J.; Kim, T.-H.; Li, G.; Oh, J.-M.; et al. Nanolayered hybrid mediates synergistic co-delivery of ligand and ligation activator for inducing stem cell differentiation and tissue healing. Biomaterials 2017, 149, 12-28. [CrossRef]

42. Yu, B.; Benning, C. Anionic lipids are required for chloroplast structure and function in Arabidopsis. Plant J. 2003, 36, 762-770. [CrossRef]

43. Kim, H.-J.; Lee, G.J.; Choi, A.-J.; Kim, T.-H.; Kim, T.-I.; Oh, J.-M. Layered Double Hydroxide Nanomaterials Encapsulating Angelica gigas Nakai Extract for Potential Anticancer Nanomedicine. Front. Pharmacol. 2018, 9. [CrossRef]

44. Elmoubarki, R.; Mahjoubi, F.Z.; Elhalil, A.; Tounsadi, H.; Abdennouri, M.; Sadiq, M.; Qourzal, S.; Zouhri, A.; Barka, N. Ni/Fe and $\mathrm{Mg} / \mathrm{Fe}$ layered double hydroxides and their calcined derivatives: Preparation, characterization and application on textile dyes removal. J. Mater. Res. Technol. 2017, 6, 271-283. [CrossRef]

45. Murase, H.; Yasuda, H.; Nakahira, A. Effect of High Magnetic Field on Ferrite Materials Obtained by Calcination of Layered Double Hydroxide. Mater. Trans. 2007, 48, 2877-2882. [CrossRef]

46. Goutelle, S.; Maurin, M.; Rougier, F.; Barbaut, X.; Bourguignon, L.; Ducher, M.; Maire, P. The Hill equation: A review of its capabilities in pharmacological modelling. Fundam. Clin. Pharmacol. 2008, 22, 633-648. [CrossRef] [PubMed]

(C) 2019 by the authors. Licensee MDPI, Basel, Switzerland. This article is an open access article distributed under the terms and conditions of the Creative Commons Attribution (CC BY) license (http://creativecommons.org/licenses/by/4.0/). 